\title{
Ideologias linguísticas e regimes de testes de língua para migrantes no Brasil
}

\section{Linguistic ideologies and language testing regimes for migrants in Brazil}

\author{
Ana Luiza Krüger Dias* \\ Universidade Federal de Goiás \\ Goiânia - Goiás / Brasil \\ Joana Plaza Pinto** \\ Universidade Federal de Goiás \\ Goiânia - Goiás / Brasil
}

\begin{abstract}
RESUMO: Neste artigo, analisamos o regime de testes de língua no contexto de migração transnacional para o Brasil e sua relação com ideologias linguísticas hegemônicas na construção de sistemas de diferenciação corporal. Para tanto, partimos da noção de teste enquanto instrumento formal para medição de proficiência, instituído como pré-requisito para entrada, residência e/ou aquisição de nacionalidade por migrantes em diversos países, funcionando como uma forma de barreira no controle das fronteiras estatais, conforme aponta a literatura pesquisada. Inicialmente, identificamos a existência de três tipos de testes linguísticos no Brasil: Certificação de Proficiência em Língua Portuguesa para Estrangeiros (Celpe-Bras), avaliação de língua portuguesa para médicos vinculados ao programa "Mais Médicos" e exigência de conhecimento de língua portuguesa nos processos de naturalização. A análise do corpus indicou diversas discrepâncias entre o estado da arte dos estudos sobre testes linguísticos em contexto migratório e a realidade brasileira, colocando em perspectiva a existência de um regime de testes linguísticos migratórios no país, na medida em que as articulações entre o seu aspecto linguístico e o seu aspecto de barreira são contraditórias. Os recursos indexicalizados nos documentos sobre testes no Brasil sinalizam, na verdade, a afirmação de uma autonomia no gerenciamento da língua portuguesa e a comoditização do ensino do português para estrangeiros como estratégia de mercado e vitrine da cultura brasileira globalizada, numa construção ideológica de correspondência estática e
\end{abstract}

\footnotetext{
*kruger.analuiza@gmail.com.

Bolsista de Iniciação Científica (CNPq), Universidade Federal de Goiás.

** joplazapinto@ufg.br.

Bolsista PQ-CNPq, Professora Associada da Universidade Federal de Goiás.
} 
naturalizada entre língua oficial e nação, produzindo, para tanto, hierarquizações entre identidades migrantes "desejáveis" e "indesejáveis".

PALAVRAS-CHAVE: Testes linguísticos; ideologias linguísticas; políticas linguísticas; migração.

\begin{abstract}
In this paper, we analyze the language testing regime in the context of transnational migration to Brazil and its relation to hegemonic linguistic ideologies in the construction of body differentiation systems. Therefore, we understand test as a formal instrument to measure proficiency, established as a pre-requisite to the entry, residence, and/or acquisition of nationality by migrants in several countries, working as a way of gatekeeping state frontiers, according to the researched literature. Initially, we identified three kinds of language tests in Brazil: the Brazilian Certificate of Proficiency in Portuguese for Foreigners (Celpe-Bras); the Portuguese test for foreign physicians within the federal government program "More Doctors for Brazil"; and the verification of Portuguese literacy in naturalization processes. The corpus analysis indicated several discrepancies between the state-of-art in the studies of language tests for migrants and the Brazilian reality, putting into perspective the very existence of a language testing regime in the country, considering that the articulations of its linguistic and gatekeeping aspects are contradictory. The resources indexed in the documents about tests in Brazil actually show the affirmation of autonomy in the management of the Portuguese language and the commodification of Portuguese teaching for foreigners as a market strategy and a showcase of a globalized Brazilian culture, in an ideological construction of static and naturalized correspondence between official language and nation, creating therefore hierarchies among "desirable" and "undesirable" migrant identities.
\end{abstract}

KEYWORDS: Language tests; language ideologies; language policy; migration.

\title{
1 Introdução
}

A contemporaneidade experimenta um crescimento cada vez maior da mobilidade espacial de pessoas, objetos e capitais simbólicos ao redor do globo. Associada às complexas dinâmicas do mercado globalizado e às forças de consumo e de comunicação digital, ela atua na direção oposta ao controle nacionalista, ameaçando padrões de estabilidade e linearidade construídos historicamente desde o século XVIII. Por essa razão, evidenciase, ao mesmo tempo, um fortalecimento na regulação de fronteiras por diversos Estados nacionais, numa tentativa de manutenção de determinados parâmetros discursivos e identitários. Blommaert (2010, p. 171) denominou essa relação que se estabelece entre a diversificação dos fluxos migratórios e o seu respectivo controle pelas instituições estatais de "resposta moderna a realidades pós-modernas". 
Neste cenário, o conceito de Estado-nação é acionado discursivamente como mobilizador de um senso de pertencimento a determinada comunidade, caracterizada por um conjunto supostamente coeso de valores e tradições culturais e linguísticas. Uma variedade linguística é vista, portanto, como algo que "pertence" a uma "comunidade de fala" definida a partir de certo espaço-tempo compartilhado (HELLER, 2008; VERTOVEC, 2011). Ocorre que quando as pessoas se movem e deslocam esse eixo espaçotemporal, seus recursos comunicativos são afetados por tais movimentos, e o que funcionaria bem numa parte do mundo pode perder sua eficácia em outra. Nessa interação entre políticas sociais e econômicas (trans)nacionais e práticas linguísticas locais, as formas de "assimilação"/"adequação" de sujeitos migrantes às novas realidades nacionais são promovidas mediante a regulação hierárquica de identidades estrangeiras "desejáveis" e “indesejáveis” (CODÓ, 2008; JACQUEMET, 2005).

As instituições estatais podem estabelecer diversos limites e gradações em termos de práticas linguísticas no território nacional, criando condições para a diferenciação de corpos falantes por meio de políticas linguísticas. As políticas linguísticas explícitas, compreendidas como normas que traçam diretrizes, regras, classificações, procedimentos e estratégias burocráticas a respeito de práticas linguísticas (BEHARES, 2011), constituem, assim, um importante locus de convergência de regimes metadiscursivos sobre línguas para contextos de migração. Trata-se de regulamentações institucionalizadas que evidenciam estruturas, estabelecem parâmetros e orientam os usos da língua e os juízos sobre esses usos em práticas específicas de interação social (SIGNORINI, 2008).

Nesses discursos oficiais, estão articuladas diversas ideologias linguísticas, entendidas como "um conjunto de crenças acerca da linguagem articuladas pelos usuários como uma racionalização ou justificação das estruturas e usos percebidos da língua"1 (SILVERSTEIN, 1979, p. 193). São elas que conferem sentido e garantem legitimidade aos padrões de diferenciação e hierarquização de práticas linguísticas, atuando como uma espécie de "mediador" metapragmático na semiose social, a partir de um sistema de referência/contextualização constituído por meio de indexicalidades pressupostas de acordo com determinadas posições ou perspectivas sociais (PINTO, 2014b; SIGNORINI, 2008).

\footnotetext{
1 "[ideologies about language, or linguistic ideologies] are any sets of beliefs about language articulated by the users as a rationalization or justification of perceived language structure and use". Todas as traduções utilizadas foram feitas para fins exclusivos deste artigo.
} 
No Brasil, as políticas linguísticas migratórias configuram-se a partir da articulação de ideologias que, por um lado, acompanham tendências internacionais de promoção de realidades multilíngues e, por outro, reproduzem consensos hegemônicos acerca do monolinguismo nacional, resultando num cenário lacunoso e generalizante (PINTO, 2014a). Considerando que os processos sociais são organizados em níveis ou camadas interacionais pelas quais sujeitos históricos circulam em termos de poder e desigualdade (BLOMMAERT et al., 2014), entende-se que quanto mais "vaga" é a voz na escala hierarquicamente superior, mais múltiplas são as vozes circulantes no outro extremo escalar. Sendo assim, entre as soluções encontradas pela administração pública, para a regulação da entrada e permanência de migrantes no território nacional, está a aplicação de variadas formas de testes de conhecimentos linguísticos.

Testes linguísticos são reconhecidos, nos discursos oficiais, como instrumentos formais de avaliação que medem as capacidades comunicativas de um indivíduo em determinada língua a partir de critérios preestabelecidos, decidindo se ele alcançou - e em que grau - as expectativas definidas para tanto, assegurando-lhe ou negando-lhe uma certificação de proficiência. ${ }^{2}$ Estudos recentes (BACHMAN; PURPURA, 2008; BLACKLEDGE, 2009; EXTRA et al., 2009; KUNNAN, 2012; MCNAMARA et al., 2015; PILLER, 2001; SHOHAMY, 2001, 2013; VAN AVERMAET, 2009) enfatizam, contudo, que, para além do propósito de medir conhecimentos linguísticos, tais testes têm o potencial de configurar-se como barreiras (gatekeepers) de acesso a direitos, principalmente em contextos de migração. Blackledge (2009), por exemplo, afirma que a aplicação de testes para migrantes constitui uma ferramenta de racialização da(s) língua(s), de modo a garantir certa "pureza” populacional. Já Shohamy (2013) destaca seu papel enquanto ferramenta de poder e controle político de realidades linguísticas, a partir do estabelecimento de padrões de práticas linguísticas desejáveis e das respectivas identidades a elas associadas.

\footnotetext{
${ }^{2}$ Conforme definido pela Unidade de Políticas Linguísticas do Conselho da Europa: "Language tests are formal instruments of assessment. They can be used either to measure proficiency without reference to a particular programme of learning or to measure the extent to which learners have achieved the goals of a specific course." Disponível em: <https://rm.coe.int/CoERMPublicCommonSearchServices/ DisplayDCTMContent?documentId=0900001680494490>. Acesso em: 9 jul. 2016.
} 
Observa-se, portanto, que os regimes de testes linguísticos para migrantes são compreendidos sob dois aspectos conceituais. O primeiro deles, associado à mensuração de um conhecimento estritamente linguístico e mais largamente utilizado por órgãos oficiais, refere-se à sua função de fornecer critérios objetivos comuns e supostamente imparciais na formação de juízos e tomadas de decisões a respeito de indivíduos em situação avaliativa. O segundo aspecto deriva da constatação da dimensão de desigualdade constitutiva estabelecida numa situação de teste, na medida em que a instância avaliadora prescreve ao avaliando uma série de tarefas para as quais ela espera uma determinada performance, a qual é estabelecida conforme critérios ideológicos excludentes (SHOHAMY, 2013). Nesse sentido, quando testes de língua são aplicados para migrantes como pré-requisito na obtenção de vistos temporários de trabalho/estudo, estabelecimento de residência permanente ou naturalização, o Estadonação está estabelecendo limites e gradações de práticas linguísticas em seu território, criando, ao mesmo tempo, condições para limitar e diferenciar corpos falantes.

Considerando que esta pesquisa propõe um olhar para o caráter multiescalar (BLOMMAERT, 2010) e superdiverso (VERTOVEC, 2007) das dinâmicas migratórias contemporâneas, nossas reflexões são orientadas pelas propostas de Van Avermaet (2009) e Piller (2001), os quais, a partir de análises de dados oficiais, categorizam diferentes tipos de testes linguísticos para diferentes gradações no vínculo estabelecido entre Estado e migrante - e sob quais condições, com quais consequências, e mobilizando quais conceitos -, conforme adiante se verá.

\section{Objetivos e metodologia}

Esta pesquisa teve por objetivos: descrever as formas de circulação dos regimes de testes de língua para migrantes no Brasil nos documentos oficiais e em sua veiculação na mídia; identificar diferentes competências e recursos comunicativos avaliados nos testes e suas inserções em diferentes ordens indexicais e sistemas de diferenciação corporal; confrontar os regimes de testes de língua para migrantes no Brasil com as ideologias linguísticas hegemônicas nacionais e transnacionais.

Para atingir os objetivos traçados, seguimos os seguintes procedimentos metodológicos: 1) revisão de literatura sobre testes de língua(s) para migrantes; 2) revisão de literatura sobre ideologias linguísticas hegemônicas 
no Brasil; 3) seleção do corpus relativo aos testes de conhecimento de língua portuguesa para migrantes no Brasil.

Para a seleção do material empírico e análise qualitativa dos elementos, foi utilizada uma metodologia de base documental a partir da base de dados do projeto principal de que esta pesquisa específica é parte, o projeto "Marcas corporais, marcas linguísticas: intersecções metadiscursivas entre línguas e corpos no Brasil". ${ }^{3}$ Considerando que, até o início da presente pesquisa, já havíamos identificado três possíveis testes migratórios, essa etapa procedimental englobou também eventuais buscas fora da base de dados (legislação e diretórios digitais de órgãos governamentais), geradas a partir do encadeamento de informações remetidas pelo próprio corpus pré-selecionado, no intuito de ampliar o material de análise. Nesta etapa, foi possível constatar a escassez e a imprecisão das informações oficiais sobre testes no Brasil, associadas às dissonâncias encontradas entre o estado da arte sobre o tema - notadamente composta por literatura sobre regimes de testes linguísticos para migrantes na Europa e nos Estados Unidos, onde tais debates são mais consolidados - e a realidade brasileira. Tais lacunas passaram, então, a configurar um importante eixo orientador das questões articuladas na análise do corpus, o qual, considerando o escopo e a base de dados disponível para esta pesquisa, ateve-se aos três testes previamente identificados.

Após este mapeamento inicial, procedemos à descrição do corpus, identificando os recursos indexicais utilizados nos documentos dos testes que apontam para as razões e os corpos que precisam se submeter a tais testes, e confrontando-os com as ideologias linguísticas nacionais e transnacionais sobre práticas em língua portuguesa.

\section{Resultados e discussão}

A revisão bibliográfica inicial sobre testes linguísticos conduziu a uma dificuldade de articular categorias de análise para esta pesquisa, em razão da diversidade tanto de cenários possíveis em dinâmicas migratórias como de elementos que elas mobilizam. Além disso, as dissonâncias entre tal conjunto bibliográfico e a realidade brasileira, associadas à precariedade de material bibliográfico específico sobre regime de testes no Brasil, geraram impasses para estabelecer as questões-chave que poderiam orientar as reflexões propostas.

${ }^{3}$ Agradecemos ao CNPq pelo apoio a esta pesquisa, em forma de bolsas e auxílio financeiro. 
A leitura dos trabalhos desenvolvidos por Van Avermaet (2009) e Piller (2001) indicou, no entanto, caminhos interessantes, haja vista que ambos estabelecem uma tipologia de testes que parte das classificações e gradações fornecidas em diversos documentos oficiais para analisá-las enquanto formas de concretização de políticas linguísticas migratórias inseridas em processos ideológicos e atreladas a determinadas noções de nacionalidade, identidade e língua. Assim, as formas como tais elementos são articulados é que determinam os requisitos linguísticos mobilizados em contextos de testes linguísticos para migrantes.

Para Van Avermaet (2009), dependendo do ponto do "caminho migratório" - ou, poderíamos dizer, nível da escala migratória - em que se encontra o indivíduo estrangeiro, quais sejam: entrar (enter), fixar residência (settle) ou requerer nacionalidade/cidadania ${ }^{4}$ (apply for citizenship) no país de destino, é possível identificar uma correspondência com os tipos de testes que lhes são aplicados, quais sejam: testes de admissão (admission), integração (integration) e naturalização (naturalisation).

Como mencionado, a investigação de possíveis formas de avaliação linguística para migrantes indicou a existência de três tipos de testes no Brasil: 1) a Certificação de Proficiência em Língua Portuguesa para Estrangeiros (Celpe-Bras); 2) a avaliação de "conhecimentos em língua portuguesa em situações cotidianas da prática médica no Brasil" para médicos intercambistas do programa federal "Mais Médicos" (art. 16, $\$ 2^{\circ}$ da Portaria Interministerial $\left.n^{\circ} 1.369 / 2013\right) ; 3$ ) a exigência de ler e escrever em língua portuguesa, comprovada pela leitura de trechos da Constituição Federal nos processos de naturalização (art. 112, IV da Lei no $6.815 / 80$ c/c art. 129, I do Decreto n ${ }^{\circ} 86.715 / 81$ ).

A partir das categorias de Van Avermaet (2009), poderíamos então classificar os tipos de testes no Brasil da seguinte maneira: o Celpe-Bras como teste de admissão, o teste para integrantes do programa "Mais Médicos" como teste de integração e o teste de português para naturalizandos/as como teste de naturalização. Nas próximas seções, colocando em perspectiva

\footnotetext{
"O termo citizenship pode designar tanto "nacionalidade" como "cidadania". Para fins das categorizações aqui esboçadas, optaremos pelo uso do termo cidadania, que remete às prerrogativas (direitos e obrigações) associadas à condição de nacional, especialmente nos casos de naturalização. Conforme se depreende do texto da Constituição Brasileira, a nacionalidade possui um sentido mais abstrato e axiológico de vinculação ao Estado (art. 12) e é pressuposto da cidadania, cujo sentido é mais político (art. $1^{\circ}$, II c/c art. 14).
} 
a própria categorização proposta, iremos descrever aspectos importantes deste corpus, identificando ordens indexicais e refletindo sobre as relações entre os recursos comunicativos avaliados nos testes e o estabelecimento de diferenciações corporais.

\subsection{Descrição do corpus}

\subsubsection{Celpe-Bras}

O site oficial do Instituto Nacional de Estudos e Pesquisas Educacionais Anísio Teixeira (Inep), vinculado ao Ministério da Educação, informa que:

O Celpe-Bras é um Exame que possibilita a Certificação de Proficiência em Língua Portuguesa para Estrangeiros. Desenvolvido e outorgado pelo Ministério da Educação (MEC), aplicado no Brasil e em outros países com o apoio do Ministério das Relações Exteriores (MRE) é o único certificado de proficiência em português como língua estrangeira reconhecido oficialmente pelo governo do Brasil. Internacionalmente, é aceito em empresas e instituições de ensino como comprovação de competência na língua portuguesa e no Brasil é exigido pelas universidades para ingresso em cursos de graduação e em programas de pósgraduação, bem como para validação de diplomas de profissionais estrangeiros que pretendem trabalhar no país. ${ }^{5}$

Diversos elementos importantes de análise estão contidos no parágrafo institucional acima transcrito. Inicialmente, importa ressaltar que sua obrigatoriedade na revalidação de diplomas estrangeiros de algumas categorias profissionais (como estabelece, por exemplo, o Conselho Federal de Medicina ${ }^{6}$ ) e na obtenção e manutenção de bolsas de estudo de graduação e pós-graduação fornecidas por convênios entre o Brasil e outros países fortaleceu o exame nos últimos anos, evidenciando-o como altamente relevante (high-stake), uma vez que decisões importantes de ordem política, econômica e educacional são tomadas a partir de seus resultados (DINIZ, 2008; BIZON, 2013).

\footnotetext{
${ }^{5}$ Disponível em: <http://celpebras.inep.gov.br/inscricao/>. Acesso em: 2 mar. 2016.

${ }^{6}$ Resolução no 1.620 , de 16 de maio de 2001.
} 
Ainda que o Celpe-Bras seja eventual e facultativamente exigido por empresas privadas na contratação de estrangeiros, sua ênfase primordial é de acesso ao mundo acadêmico. O Programa Federal de Estudantes - Convênio de Graduação (PEC-G) e de Pós-Graduação (PEC-PG), sob gerência da CAPES (Coordenação de Aperfeiçoamento de Pessoal de Ensino Superior), que exige como pré-requisito ao aluno estrangeiro a aprovação no exame, apresenta-se como importante instrumento de política pública voltado à mobilidade de estudantes do eixo sul-sul, consolidando relações econômicoculturais com os países conveniados. Conforme aponta Bizon (2013, p. 53), "nota-se, por parte do governo brasileiro, o claro objetivo de marcar, de modo devidamente documentado e, portanto, definitivo, seu investimento nesses países".

A estrutura do exame encontra-se bastante detalhada nos materiais oficiais, os quais enfatizam a relação entre língua, identidade e cultura. Segundo o Guia de Capacitação para Examinadores do Celpe-Bras (BRASIL, 2013b, p. 7), "a proficiência do examinando é avaliada pelo seu desempenho em tarefas comunicativas semelhantes a situações que podem ocorrer no cotidiano de um estrangeiro que pretende interagir em português", verificando-se sua capacidade de se comunicar "com os conhecimentos de que dispõe acerca da língua e sobre os rituais sociais que regulam a interlocução". Segundo a documentação da página eletrônica do CelpeBras, os examinandos devem responder a uma série de questões escritas e orais a partir de "elementos provocadores", os quais seguem um "roteiro de interação face a face" disponibilizado aos examinadores e responsável por conduzir as formas pelas quais tais elementos serão discutidos.

Os elementos provocadores constituem-se de temas caracteristicamente associados à contemporaneidade a partir das formas como eles são mobilizados no contexto brasileiro. Como confirmado na pesquisa de Diniz (2008), os temas englobam certo discurso de "brasilidade", como a culinária nacional (tema do teste de 2013-1) e o futebol (tema do teste de 2014-1). Mas, recentemente, a inserção do Brasil nos processos de globalização contemporânea ganha cada vez mais espaço no teste, incluindo então temas como internet e tecnologia (tema do teste de 20151) e sustentabilidade (tema do teste de 2016-1), e temas que caracterizam a "brasilidade" como "transnacional", como a plataforma de interação criada por brasileiros (tema do teste de 2015-1) e o turismo esportivo praticado por brasileiros no exterior (tema do teste de 2016-1). 
As descrições contidas em documentos oficiais deixam claro que o Celpe-Bras se vincula a um projeto de promoção da língua nacional. Sendo o principal instrumento de avaliação em língua portuguesa para estrangeiros no país, tem como efeito principal pautar retroativamente o ensino de português em cursos preparatórios para o próprio exame, disponíveis em universidades e embaixadas brasileiras e instituições estrangeiras. Tratase, ao mesmo tempo, de uma estratégia de mercado e de consolidação de uma posição de autonomia do Estado Brasileiro, "não apenas em relação à produção de um saber metalinguístico sobre o português, mas também em relação à gestão dessa língua no cenário geopolítico internacional" (DINIZ, 2012, p. 452-453).

\subsubsection{Mais Médicos}

Assim como o Celpe-Bras, a avaliação de conhecimentos em língua portuguesa para médicos intercambistas do programa "Mais Médicos" está inserida num amplo conjunto de ações de caráter educacional do Estado brasileiro. No portal eletrônico do programa, informa-se que:

O Módulo de Acolhimento e Avaliação dos médicos intercambistas [...] utiliza a combinação de momentos de concentração presencial com outros de Ensino a Distância, onde o aprendizado de Língua Portuguesa num enfoque mais instrumental para a comunicação médica será trabalhado em caráter longitudinal ao longo de todos os três anos de atuação do médico no projeto.?

Percebe-se que este teste de língua portuguesa a médicos estrangeiros tem como objetivo checar sua aprendizagem ao final de um curso, no âmbito do qual o ensino linguístico está completamente atrelado a conteúdos de prática médica. Em nota de setembro de 2013 sobre o módulo de acolhimento e avaliação realizado na primeira etapa do programa, ${ }^{8}$ o MEC enfatizou sua natureza de avaliação continuada, destacando que ele "servirá como linha de base para melhor desempenho no curso de especialização

\footnotetext{
${ }^{7}$ Disponível em: <http://portalsaude.saude.gov.br/index.php/cidadao/acoese-programas/mais-medicos/mais-sobre-mais-medicos/5958-medicos-curso-deacolhimento>. Acesso em: 2 mai. 2016.

${ }^{8}$ Disponível em: < http://portal.mec.gov.br/component/content/article?id=19074:notasobre-o-modulo-de-acolhimento-e-avaliacao>. Acesso em 2 mai. 2016.
} 
em Atenção Básica que ocorrerá ao longo dos três anos de participação do profissional no programa Mais Médicos”.

Ao contrário do Celpe-Bras, as informações oficiais relativas ao teste de língua do programa "Mais Médicos" são bastante imprecisas e pulverizadas na documentação. No entanto, o assunto é altamente veiculado na mídia, por meio de um discurso que utiliza a língua portuguesa como âncora a críticas de natureza político-ideológica ao programa, conforme notamos neste editorial da Revista da Associação Médica Brasileira (AMB):

Há estudos científicos indicando que a barreira da língua está associada ao recebimento de $50 \%$ a menos de analgésico após fraturas em ossos longos [...] à menor aderência ao tratamento (fazer o que o médico orientou), ao triplo de faltas às consultas de seguimento nos casos de pacientes com asma [...] menor satisfação por parte dos pacientes e menor taxa de explicação com relação a eventuais efeitos colaterais de medicamentos [...]. A autorização para o exercício da Medicina de médicos sem treinamento adequado e sem razoável ambientação cultural e linguística não está baseada nem em experiências empíricas nem em evidências científicas (CARAMELLI, 2013, p. 408).

O trecho transcrito indicia elementos da ideologia monolíngue como forma de barrar a atuação de médicos migrantes no país, recorrendo, para tanto, à noção de correspondência total entre competência linguística e profissional. Assim, segundo a estratégia discursiva do editorial, a falta de conhecimentos em língua portuguesa configura-se como barreira na medida em que inevitavelmente converte-se em prática reiterada de erros médicos, representando, portanto, grave risco à saúde dos pacientes. A suposta necessidade de "ambientação cultural e linguística", não definida claramente, evidencia que a integração desejável de migrantes se dá pelo apagamento das diferenças no intuito de garantir harmonia e coesão sociais.

\subsubsection{Naturalização}

No Brasil, o Estatuto do Estrangeiro (Lei no 6.815/80, art. 112, IV) estabelece como requisito para a concessão da naturalização "ler e escrever a língua portuguesa", o qual era demonstrado mediante "leitura de trechos da Constituição" (Decreto no 86.715/81, art. 129, I). Esta configuração normativa ensejava múltiplas possibilidades de avaliação de proficiência pelo juiz na audiência, já que não há um sistema de critérios comuns para fins 
avaliativos, a não ser um modelo grafocêntrico que sustenta as ideologias linguísticas no Brasil, ou seja, a ideia de que saber a língua portuguesa é saber ler e escrever nesta língua (PINTO, 2014b; SIGNORINI, 2002). A jurisprudência a seguir, de negação de nacionalidade a um migrante libanês, é elucidativa nesse aspecto:

Embora tenha este Juízo colhido prova testemunhal e obtido declarações de que o Autor possui renda própria suficiente para prover a sua subsistência e que também é capaz de ler e escrever o idioma nacional, não pode substituir a decisão administrativa [...]. Por tratar-se de ato discricionário, não se vislumbra ilegitimidade, pois o Poder Executivo, por decisão fundamentada, indeferiu o requerimento do Autor dentro do âmbito que possui de conveniência e oportunidade, binômio próprio dos atos discricionários. (BRASIL, 2007)

No entanto, o dispositivo que estabelecia que a demonstração de conhecimento de língua portuguesa se fazia mediante a leitura de trechos da Constituição foi revogado no decorrer desta pesquisa pelo Decreto $n^{\circ} 8.757$, de 10 de maio de 2016, que alterou algumas regras relativas à situação jurídica do estrangeiro no país. Tais alterações refletem um cenário de mudanças legislativas em curso sobre a matéria. Em 2017, tramitam no Congresso Nacional o Projeto de Lei no 5.655/2009 e o Projeto de Lei do Senado n ${ }^{\circ}$ 288/2013, que visam a substituir o atual Estatuto do Estrangeiro e cujas propostas apontam para uma política estratégica de atração e retenção de migrantes qualificados por meio da desburocratização.

A maioria das alterações previstas pelo decreto recente ainda dependerão de Resolução Normativa do Conselho Nacional de Imigração para regular o procedimento dos atos, os quais, por ora, são realizados através do arbítrio dos agentes estatais. Considerando, ainda, que não encontramos nenhuma informação oficial detalhada a respeito do procedimento avaliativo da língua portuguesa para concessão da naturalização, podemos afirmar que ele se mostra um ato de caráter altamente discricionário, em que a figura do juiz, a partir de critérios por ele definidos segundo oportunidade e conveniência, irá determinar o nível de proficiência do naturalizando, concedendo-lhe ou negando-lhe a nacionalidade brasileira. 


\subsection{Repensando o conceito de teste linguístico}

Conforme mencionado, o conceito de teste linguístico aplicado a contextos de migração é construído a partir do entrelaçamento de dois aspectos constitutivos, quais sejam, um aspecto estritamente linguístico e outro aspecto ampliativo de tal noção acerca do "linguístico", o qual concebe a avaliação da proficiência de migrantes como uma forma de barrar seu acesso a determinados níveis da escala social. Tal entrelaçamento permite uma classificação dos testes a partir da correspondência entre a mobilidade escalar pretendida pelo sujeito migrante e as exigências linguísticas que este deve satisfazer para tanto.

Nesse ponto, Piller (2001) faz uma distinção útil entre o que denomina de cidadania "espessa" (thick citizenship) - relacionada com um sentimento de pertencimento total à nação - e cidadania "estreita" (thin citiženship) - um sentimento de estranheza com relação à nação. Cidadãos nativos de gênero, raça e classe privilegiados estariam localizados no extremo "espesso" dessa escala, enquanto estrangeiras/os não naturalizadas/os, não documentadas/ os e pertencentes a grupos discriminados localizam-se no extremo oposto. O requerimento de naturalização seria, por exemplo, um passo da escala estreita em direção à espessa.

Os elementos que circunscrevem os sujeitos nessa escala são diversificados e complexos, e dependem das formas como as ideologias linguísticas se articulam no país, bem como as formas como tais sujeitos vivenciam a migração. Piller (2001) destaca, por exemplo, que em Israel o pertencimento nacional é largamente baseado em filiações religiosas e étnicas, em lugar do conhecimento da língua hebraica. Países com larga experiência de imigração (Austrália, Canadá e Estados Unidos) definem a nacionalidade/cidadania com base em direitos e deveres. Os testes de língua servem, nesses casos, para mostrar que o requerente tem conhecimento suficiente da língua para cumprir seus deveres e defender seus direitos institucionalmente, razão pela qual as habilidades são testadas a partir de questões relativas a normas e deveres cívicos. Na França, considera-se que o critério-chave de pertencimento nacional é a cultura francesa, funcionando a língua como um canal de acesso a ela. $\mathrm{Na}$ Alemanha, a identidade nacional foi historicamente baseada no critério da ancestralidade, o que praticamente excluía o próprio processo de naturalização até o ano 2000 (que só era adquirida, com pouquíssimas exceções, por ascendência, gerando populações inteiras não falantes de alemão). 
$\mathrm{Na}$ esteira dessa diversidade de critérios, a descrição do material empírico relativo a testes linguísticos no Brasil demonstrou que a classificação geralmente adotada na literatura não se encaixa propriamente à realidade do regime de testes brasileiro. Observa-se que o Celpe-Bras não necessariamente impede a entrada de migrantes no país, ou seja, não é critério indispensável para que o migrante receba um "carimbo" em seu passaporte na alfândega. Da mesma forma, a avaliação de médicos estrangeiros vinculados ao programa "Mais Médicos" não é condição essencial para que estes fixem residência permanente no país. Nesse cenário, apenas os casos de naturalização podem se encaixar na tipologia proposta, na medida em que podem permitir ou impedir a aquisição de nacionalidade brasileira com base na língua. De qualquer forma, é necessário acompanhar as repercussões das recentes mudanças legislativas a respeito da matéria para observar como o teste passará a funcionar.

No entanto, mais do que um desencaixe relativo à tipologia dos testes, as discrepâncias entre a análise do corpus e o estado da arte de estudos sobre testes nos levaram a questionar sobre a existência de um regime de testes linguísticos migratórios no Brasil, colocando em perspectiva, assim, a própria noção do que são testes linguísticos.

\subsubsection{Há um regime de testes linguísticos para migrantes no Brasil?}

Considerando a dupla articulação do conceito de testes linguísticos migratórios adotada neste trabalho, duas questões se tornam fundamentais para a identificação de um regime de testes migratórios num país: as avaliações destinadas a migrantes têm caráter linguístico? Elas se configuram como barreiras? As possíveis respostas a tais questões conduziram a importantes ressignificações para a pesquisa realizada.

De início, percebe-se que o Celpe-Bras é o exame de língua portuguesa para estrangeiros mais detalhado, mais padronizado, mais divulgado e mais regulamentado nos discursos oficiais brasileiros, sendo o único que se que coaduna com o conceito tradicional de instrumento formal destinado a medir conhecimentos linguísticos. No programa "Mais Médicos", a língua portuguesa é um dos eixos que compõem a formação dos médicos intercambistas, sendo que avaliação ao final do módulo de acolhimento do programa concebe a importância do uso da língua desde que atrelada a conteúdos de prática médica. Já a avaliação do português para a concessão de naturalização não obedece nenhum sistema de critérios objetivos, 
ficando essa aferição ao arbítrio discricionário do juiz, o qual, conforme se depreende da jurisprudência apontada como exemplo, pode não ser estritamente linguístico.

Tais constatações sobre o caráter linguístico dos testes ocorrem em aparente contradição ao aspecto de barreira normalmente atribuído a eles. Assim, observa-se que, dentre os instrumentos analisados na pesquisa, o Celpe-Bras, apesar de extensamente normatizado, é aquele que menos configura um possível impedimento para entrada/permanência de migrantes no país. Seu efeito retroativo enquanto plataforma para pautar cursos de língua portuguesa para estrangeiros evidencia inserção do exame numa complexa rede de instituições e serviços que visam à internacionalização da língua portuguesa do Brasil. A oferta de cursos preparatórios por universidades brasileiras para alunos estrangeiros que pretendem pleitear uma vaga no PEC-G/PEC-PG, por exemplo, já possibilita seu acesso e vivência no ambiente acadêmico brasileiro, bem como sua vinculação institucional àquela universidade. Percebe-se que uma possível reprovação no Celpe-Bras em momento posterior, ainda que implique na não vinculação do migrante àquela universidade via PEC-G/PEC-PG, não impede a mobilidade desses estudantes estrangeiros no país.

O que está em questão aqui, portanto, é o gesto político do Estado brasileiro em relação à inclusão do português do Brasil em um espaço geopolítico transnacional, vinculado a um projeto de promoção da língua nacional. O contexto e as configurações do teste parecem funcionar como vitrine de divulgação da cultura brasileira pelo globo e de autonomia na gestão dessa língua no cenário geopolítico internacional (DINIZ, 2012), assim como faz jus a uma inserção da língua portuguesa no mercado transnacional de ensino de línguas de migração para o trabalho, como mostra a tendência de aumento, ao longo dos anos, de questões sobre mercado de trabalho no material do teste disponível online.

Com relação ao projeto "Mais Médicos", nota-se que, em caso de reprovação no módulo de acolhimento e avaliação, o médico intercambista será imediatamente desligado do projeto. Aqui, o caráter de barreira é restrito à participação no programa, não impedindo a integração daquele migrante, ou mesmo o exercício da medicina no país, por outras vias. O conhecimento do português parece ser um problema maior fora do âmbito institucional do programa, sendo "avaliado" continuamente na mídia (especialmente em textos de opinião), como forma de hierarquizar identidades estrangeiras. 
Já a avaliação de conhecimento de língua portuguesa em casos de naturalização é aquela que mais se configura como barreira para aquisição de direitos de migrantes, na medida em que pode impedir sua mobilidade na escala de cidadania. Ao mesmo tempo, é o tipo de teste menos regulamentado e menos fundamentado em critérios estritamente linguísticos. Neste tipo de teste, observamos que o conceito de língua pode ser acionado metapragmaticamente para justificar a decisão denegatória do julgador, tratando-se, na maioria dos casos, de mera formalidade ritualística (nem sempre observada, aliás).

As múltiplas configurações do regime de testes brasileiro parecem indicar, nesse sentido, que não se trata de um regime de testes nos moldes teóricos tradicionais, na medida em que o aspecto estritamente linguístico da avaliação não se articula com o seu uso enquanto barreira à entrada/ permanência/cidadania de migrantes no país. Na realidade, os testes ora analisados parecem sinalizar uma tentativa de afirmação do país num cenário internacional superdiverso pela via da promoção da língua portuguesa, numa construção ideológica de correspondência estática e naturalizada entre língua oficial e nação.

Ao mesmo tempo, o conceito de teste continua a ser acionado discursivamente por meio de recursos metapragmáticos no âmbito institucional e extrainstitucional quando se trata da negociação da mobilidade escalar de migrantes "desejáveis" e "indesejáveis". Este é o caso evidente do editorial da Revista da AMB, o qual, ao avaliar práticas de uso oral e escrito da língua portuguesa por médicos migrantes, instancia discursos sobre a centralidade de uma cultura supostamente homogênea ("bagagem cultural" a ser reconhecida por médicos brasileiros "atentos") no conhecimento linguístico, ao mesmo tempo em que constrói como pano de fundo do seu texto a superioridade da literatura sobre os demais conhecimentos linguísticos - deslizando para o mito da língua portuguesa difícil ("as dificuldades da língua portuguesa, diferente e estranha"). Numa estratégia de hierarquização corporal, o editorial parece expandir a "bagagem cultural" como diversa e multifacetada, mas ao mesmo tempo deixa implícito que para ser um bom médico no Brasil é preciso conhecer "geografia", "história do Brasil", "Guimarães Rosa".

Nesses discursos, articulam-se as ideologias linguísticas do monolinguismo nacional, da superioridade da norma literária sobre as práticas orais e da correspondência naturalizada entre língua, cultura e nação, de papel relevante para a "institucionalização de mecanismos sociais 
de regulamentação, controle e valoração do acesso, produção, consumo e circulação dos recursos linguístico-discursivos” (SIGNORINI, 2008, p. 119).

As hierarquizações entre usos e formas linguísticas e os padrões socioculturais de diferenciação de corpos migrantes se sustentam mutuamente. Assim, o aparente incentivo à assimilação ou integração do estrangeiro por meio do aprendizado da língua nacional e de sua cultura supostamente homogênea, associado à aparente neutralidade das instâncias oficiais e à despolitização das diferenças, emerge assim como estratégia de coexistência "harmônica" diante da heterogeneidade social (CODÓ, 2008).

Tais reflexões indicam que, subjacentes às políticas linguísticas explícitas nacionais, diversas ideologias linguísticas se sobrepõem e se contradizem, requerendo ressignificações teóricas sobre a noção de testes linguísticos a partir das tensões produzidas entre a tendência à heterogeneidade e a persistência da uniformidade, por meio das quais se constroem as relações entre língua, Estado e ideologia na contemporaneidade.

\section{Considerações finais}

No decorrer desta pesquisa, deparamo-nos, fundamentalmente, com duas espécies de conflitos entre a geração de dados sobre testes linguísticos e o estado da arte. A primeira delas diz respeito à escassez de dados empíricos sobre regimes de testes aplicados no Brasil, bem como seu caráter impreciso. Quando confrontados, por exemplo, com conversas informais com migrantes que vivenciaram situações de teste, é possível, além de acessar diversas informações não disponíveis “oficialmente", perceber como são variadas as ações institucionais e não institucionais nesse campo e as visões que os sujeitos carregam sobre teste, língua e identidade. A segunda espécie de conflito com a qual deparamos diz respeito ao fato de que a literatura sobre o tema - em sua maior parte, relativa às realidades europeias, onde a cultura de testes é mais consolidada - não se "encaixa" propriamente com os dados relativos às realidades brasileiras.

Num sistema burocrático complexo e escalar como o apresentado, o fracionamento da informação pode funcionar, conforme notamos, como apagamento de contradições e uniformização do entendimento sobre ele, conduzindo a modos de proceder previsíveis e desejáveis. Assim, a diversidade de critérios e práticas encontrados aponta a complexidade das ideologias linguísticas e nacionais em questão, ao mesmo tempo em que aponta uma tendência comum: o objetivo dos testes de língua para migrantes 
não é necessariamente estabelecer um padrão objetivo de proficiência, mas manter a divisão entre nacionais e não nacionais, salvaguardando os privilégios dos primeiros e eliminando identidades estrangeiras não desejáveis (PILLER, 2001).

Os casos analisados no presente trabalho indicam, assim, que a análise de contextos migratórios não pode mais se basear nos modelos tradicionais de interpretação das migrações a partir da estabilidade, mas assimilar as complexidades e contingências de contextos superdiversos, cujas interações linguísticas são organizadas em níveis escalares variados e imprevisíveis, ainda que altamente regulados (BLOMMAERT, 2010; VERTOVEC, 2007).

Diante desse cenário, reconhecemos a necessidade de ampliação do foco empírico para este campo de estudo. Considerando que competências e recursos comunicativos em contextos migratórios são avaliados a partir de diferentes ordens indexicais e que a intrincada relação entre língua e identidade não se faz apenas nas políticas linguísticas explícitas, mas também nos usos e interações linguísticas entre corpos falantes, uma próxima etapa de pesquisa fará uma investigação de caráter etnográfico com vistas a possibilitar o cruzamento de aspectos macro e micro contextuais que enquadram a experiência de migrantes e indiciam diferenças e desigualdades de direitos sociais, econômicos, educacionais e, obviamente, linguísticos.

\section{Referências}

BACHMAN, L. F.; PURPURA, J. E. Language Assessments: Gate-Keepers or Door-Openers? In: SPOLSKY, B.; HULT, F. M. (Ed.). The Handbook of Educational Linguistics. Oxford: Blackwell, 2008. p. 456-468.

BEHARES, L. E. (Org.). V Encuentro Internacional de Investigadores de Politicas Lingüísticas. Montevideo: Asociación de Universidades Grupo Montevideo, 2011. BIZON, A. C. C. Narrando o exame Celpe-Bras e o convênio PEC-G: a construção de territorialidades em tempos de internacionalização. 2013. 445 f. Tese (Doutorado em Linguística Aplicada) - Instituto de Estudos da Linguagem, Universidade de Campinas, Campinas, 2013.

BLACKLEDGE, A. Inventing English as Convenient Fiction: Language Testing Regimes in the United Kingdom. In: EXTRA, G.; SPOTTI, M.; AVERMAET, P. V. (Ed.). Language Testing, Migration and Citizenship: Cross-National Perspectives on Integration Regimes. London: Continuum, 2009. p. 66-86.

BLOMMAERT, J. The Sociolinguistics of Globalization. New York: Cambridge University Press, 2010. 
BLOMMAERT, J.; WESTINEN, E.; LEPPÄNEN, S. Further Notes on Sociolinguistic Scales. Tilburg Papers in Culture Studies, Tilburg, paper 89, p. 1-11, jan. 2014.

BRASIL. Conselho Federal de Medicina. Resolução no 1.620, de 16 de maio de 2001. Diário Oficial da União, Brasilia, DF, 6 jun. 2001. Seção 1, p. 40. Disponível em: <http://bit.ly/2jmUZza>. Acesso em: 27 jan. 2017.

BRASIL. Constituição da República Federativa do Brasil, de 05 de outubro de 1988. Disponível em: < http://bit.ly/1dFiRrW>. Acesso em: 27 jan. 2017.

BRASIL. Decreto no 8.757, de 10 de maio de 2016. Altera o Decreto no 86.715, de 10 de dezembro de 1981, para dispor sobre a situação jurídica do estrangeiro na República Federativa do Brasil. Diário Oficial da União, Brasília, DF, 11 maio 2016. Seção 1, p. 6. Disponível em: <http:/ / bit.ly/2jFtyBx>. Acesso em: 27 jan. 2017.

BRASIL. Decreto no 86.715, de 10 de dezembro de 1981. Regulamenta a Lei $\mathrm{n}^{\circ}$ 6.815, de 19 de agosto de 1980, que define a situação jurídica do estrangeiro no Brasil, cria o Conselho Nacional de Imigração e dá outras providências. Diário Oficial da União, Brasília, DF, 11 dez. 1981. Seção 1, p. 23496. Disponível em: < http:/ / bit. ly/2jn2iXI>. Acesso em: 27 jan. 2017.

BRASIL. Lei $\mathrm{n}^{\circ} 12.871$, de 22 de outubro de 2013. Institui o Programa Mais Médicos, altera as Leis $n^{\circ} 8.745$, de 9 de dezembro de 1993, e nº 6.932, de 7 de julho de 1981, e dá outras providências. Diário Oficial da União, Brasília, DF, 23 out. 2013 a. Seção 1, p. 1. Disponível em: <http://bit.ly/1kBwlJj>. Acesso em: 27 jan. 2017.

BRASIL. Lei n ${ }^{\circ}$ 6.815, de 19 de agosto de 1980. Define a situação jurídica do estrangeiro no Brasil, cria o Conselho Nacional de Imigração. Diário Oficial da União, Brasília, DF, 21 ago. 1980. Seção 1, p. 16533. Disponível em: <http://bit.ly/ Uodnvi>. Acesso em: 27 jan. 2017.

BRASIL. Ministério da Educação. Guia de capacitação para examinadores da parte oral do Celpe-Bras: Certificado de Proficiência em Língua Portuguesa para Estrangeiros. Brasília, DF: Instituto Nacional de Estudos e Pesquisas Educacionais Anísio Teixeira, 2013b.

BRASIL. Ministério da Educação. Portaria nº 1.350, de 25 de novembro de 2010. Dispõe sobre o Exame para Certificação de Proficiência em Língua Portuguesa para Estrangeiros - Celpe-Bras. Diário Oficial da União, Brasília, DF, 26 nov. 2010. Seção 1, p. 226. Disponível em: <http:/ / bit.ly/2jFFi7a>. Acesso em: 27 jan. 2017. BRASIL. Ministérios da Saúde e da Educação. Portaria Interministerial no 1.369, de 8 de julho 2013. Dispõe sobre a implementação do Projeto Mais Médicos para o Brasil. Diário Oficial da União, Brasília, DF, 9 jul. 2013c. Seção 3, p. 125. Disponível em: <http://bit.ly/1dhEAbj>. Acesso em: 27 jan. 2017. 
BRASIL. Tribunal Regional Federal (4. Região). Apelação cível n ${ }^{\circ}$ 2006.70.02.003021-0-PR. Apelante: Adnan Fayez Charrouf. Apelado: União Federal. Relatora: Desembargadora Federal Maria Lúcia Luz Leiria. Porto Alegre, 16 de junho de 2009. Diário Eletrônico da 4. Região, n. 295, de 24 de dezembro de 2007. Disponível em: < http://bit.ly/2kBB00H>. Acesso em: 27 jan. 2017.

CARAMELLI, B. Os médicos estrangeiros: a questão da língua. Revista da Associação Médica Brasileira, São Paulo, v. 59, n. 5, p. 407-408, 2013.

CODÓ, E. Immigration and Bureaucratic Control: Language Practices in Public Administration. Berlin: Mouton de Grutyer, 2008.

DELL'ISOLA, R. L. P.; SCARAMUCCI, M. V. R.; SCHLAT'TER, M.; JÚDICE, N. A avaliação de proficiência em português língua estrangeira: o exame CELPE-Bras. Revista Brasileira de Linguística Aplicada, Belo Horizonte, v. 3, n. 1, p.153-164, 2003.

DINIZ, L. R. A. Mercado de línguas: a instrumentalização brasileira do português como língua estrangeira. 2008. 201 f. Dissertação (Mestrado em Linguística) Instituto de Estudos da Linguagem, Universidade de Campinas, Campinas, 2008. DINIZ, L. R. A. Política linguística do Estado brasileiro para a divulgação do português em países de língua oficial espanhola. Trabalhos em Linguística Aplicada, Campinas, v. 51, n. 2, p. 435-458, jul./dez. 2012.

DUCHÊNE, A.; MOYER, M.; ROBERTS, C. (Ed.). Language, Migration and Social Inequalities: a Critical Sociolinguistic Perspective on Institutions and Work. Bristol: Multilingual Matters, 2013.

EXTRA, G.; SPOTTI, M.; VAN AVERMAET, P. . Testing regimes for newcomers. In: EXTRA, G.; SPOTTI, M.; AVERMAET, P. V. (Ed.). Language Testing, Migration and Citizenship: Cross-National Perspectives on Integration Regimes. London: Continuum, 2009. p. 3-33.

HELLER, M. Language and the Nation-State: Challenges to Sociolinguistic Theory and Practice. Journal of Sociolinguistics, Hoboken, v. 12, n. 4, p. 504-524, 2008.

JACQUEMET, M. Transidiomatic Practices: Language and Power in the Age of Globalization. Language \& Communication, Amsterdam, v. 25, p. 257-277, 2005.

KUNNAN, A. J. Language Assessment for Immigration and Citizenship. In: FULCHER, G.; DAVIDSON, F. (Ed.). The Routledge Handbook of Language Testing. New York: Routledge, 2012. p. 162-177.

MCNAMARA, T.; KHAN, K.; FROST, K. Language Tests for Residency and Citizenship and the Conferring of Individuality. In: SPOLSKY, B.; INBARLOURIE, O.; TANNENBAUM, M. (Ed.). Challenges for Language Education and Policy: Making Space for People. New York: Routledge, 2015. p. 11-22. 
PILLER, I. Naturalization Language Testing and its Basis in Ideologies of National Identity and Citizenship. The International Journal of Bilingualism, Thousand Oaks, v. 5, n. 3, p. 259-277, 2001.

PINTO, J. P. Contradições e hierarquias nas ideologias linguísticas do Conselho Nacional de Imigração. Domínios de Lingu@gem, Uberlândia, v. 8, n. 3, p. 108-134, ago./dez. 2014a.

PINTO, J. P. Hegemonias, contradições e desafios em discursos sobre língua no Brasil. In: CORREA, D. A. (Org.). Política linguística e ensino de lingua. Campinas: Pontes Editores, 2014b. p. 59-72.

SHOHAMY, E. The Discourse of Language Testing as a Tool for Shaping National, Global, and Transnational Identities. Language and Intercultural Communication, Abingdon, v. 13, n. 2, p. 225-236, 2013.

SHOHAMY, E. The power of tests: A critical perspective on the uses of language tests. Harlow: Longman, 2001.

SIGNORINI, I. Metapragmáticas da língua em uso: unidades e níveis de análise. In: SIGNORINI, I. (Org.). Situar a lingua[gem]. São Paulo: Parábola Editorial, 2008. p. 117-148.

SIGNORINI, I. Por uma teoria da desregulamentação linguística. In: BAGNO, M. (Org.). Linguística da norma. São Paulo: Edições Loyola, 2002. p. 93-125.

SILVERSTEIN, M. Language Structure and Linguistic Ideology. In: CLYNE, P. R.; HANKS, W. F.; HOFBAUER, C. L. (Ed.). The Elements: a Parasession on Linguistic Units and Levels. Chicago: Chicago Linguistic Society, 1979. p. 193-247.

SILVERSTEIN, M. The Uses and Utility of Ideology: Some Reflections. Pragmatics, Amsterdam, v. 2, n. 3, p. 311-323, 1992.

VAN AVERMAET, P. Fortress Europe? Language policy regimes for immigration and citizenship. In: HOGAN-BRUN, Gabrielle; MAR-MOLINERO, Clare; STEVENSON, Patrick (eds.). Discourses on language and integration: critical perspectives on language testing in Europe. Amsterdam: John Benjamins, 2009. p. 15-44.

VERTOVEC, S. Super-Diversity and its Implications. Ethnic and Racial Studies, Abingdon, v. 30, n. 6, p. 1024-1054, nov. 2007.

VERTOVEC, S. The Cultural Politics of Nation and Migration. Annual Review of Anthropology, Palo Alto, v. 40, p. 241-256, 2011.

Data de submissão: 24/08/2016. Data de aprovação: 02/02/2017. 